\title{
Busca por cuidados de saúde: itinerário terapêutico de crianças egressas de unidades neonatais
}

\section{Search for health care: therapeutic itinerary of children discharged from the neonatal units}

\section{Búsqueda de cuidados de salud: itinerario terapéutico de niños de alta de unidades neonatales}

\author{
Hortênsia Coutinho da Rocha iD \\ Universidade Federal do Maranhão - São Luiz (MA) - Brasil
}

\section{Zeni Carvalho Lamy (iD)}

Universidade Federal do Maranhão - São Luiz (MA) - Brasil

Lia Cardoso de Aguiar (iD

Universidade Federal do Maranhão - São Luiz (MA) - Brasil

Joama Gusmão Pereira Moreira (iD

Universidade Federal do Maranhão - São Luiz (MA) - Brasil

\section{Marina Uchoa Lopes Pereira iD}

Universidade Federal do Maranhão - São Luiz (MA) - Brasil

Universidade Estadual de Campinas - Campinas (SP) - Brasil

Yanca Lacerda Albuquerque (iD

Universidade Federal do Maranhão - São Luiz (MA) - Brasil

Tadeu de Paula Souza iD

Universidade Federal do Rio Grande do Sul - Porto Alegre (RS) - Brasil

Fernando Lamy Filho

Universidade Federal do Maranhão - São Luiz (MA) - Brasil

\section{RESUMO}

Objetivo: Compreender os caminhos percorridos por mães e cuidadoras na busca pelo cuidado de crianças egressas de unidades neonatais. Métodos: Estudo qualitativo e exploratório, realizado entre maio e junho de 2018, com mães e cuidadoras de crianças nascidas entre 2014 e 2015 , egressas de duas unidades neonatais públicas de uma capital do Nordeste brasileiro. Realizaram-se 14 entrevistas semiestruturadas, e se utilizou análise de conteúdo na modalidade temática. Apreenderam-se três categorias que evidenciam possíveis caminhos percorridos para o cuidado, perpassando, em sua maioria, pelos três setores: "O setor informal como ponto de partida para o cuidado", "O uso do setor popular como prática de cura", "O uso do setor profissional: alternativa para consulta". Resultados: O setor informal foi o mais relatado pelas cuidadoras. Em geral, a primeira escolha era pela automedicação orientada de forma transgeracional, pelas avós. $O$ uso do setor popular foi influenciado pelo conhecimento prévio das famílias e sua percepção do processo saúde-doença. A cultura biomédica perpassou os três setores e influenciou na construção do itinerário terapêutico. No setor profissional identificou-se vínculo frágil, principalmente na atenção primária. Conclusão: Os caminhos percorridos por mães e cuidadoras de egressos de unidades neonatais apontaram sobreposição da medicalização em detrimento dos saberes populares. Acolher e manejar os repertórios sociais e culturais das famílias pode contribuir para fortalecer vínculos terapêuticos com o setor profissional. AAtenção Primária à Saúde precisa ser fortalecida para garantir a qualificação do cuidado às crianças.

Descritores: Atenção à Saúde; Cuidado da Criança; Medicina Tradicional; Automedicação; Unidades de Terapia Intensiva Neonatal.

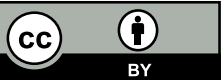




\section{ABSTRACT}

Objective: To understand the paths taken by mothers and caregivers while searching for care for children discharged from neonatal units. Methods: Qualitative and exploratory study, carried out between May and June 2018, with mothers and caregivers of children born between 2014 and 2015, discharged from two public neonatal units in a capital from a Northeastern Brazil state. Fourteen semi-structured interviews were conducted, and content analysis was used in the thematic modality. Three categories were found that show possible paths taken for the care, mostly passing through the three sectors: "the informal sector as a starting point for the care", "the use of the popular sector as a healing practice", and "the use of professional sector: an alternative for consultation". Results: The informal sector was the most addressed sector by caregivers. In general, the first choice was for self-medication oriented transgenerationally by grandmothers. The use of the popular sector was influenced by the families' prior knowledge and their perception of the health-disease process. Biomedical culture permeated the three sectors and influenced the construction of the therapeutic itinerary. In the professional sector, a fragile bond was identified, mainly in primary care. Conclusion: The paths taken by mothers and caregivers of newborns discharged from neonatal units pointed to an overlap of medicalization to detriment of popular culture. Hosting and managing families' social and cultural repertoires contribute to strengthening therapeutic links with the professional sector. Primary Health Care needs to be strengthened to guarantee the qualification of care for children.

Descriptors: Health Care; Child Care; Traditional Medicine; Self-medication; Intensive Care Units, Neonatal.

\section{RESUMEN}

Objetivo: Comprender los caminos recorridos por madres y cuidadoras para la búsqueda del cuidado de niños de alta de unidades neonatales. Métodos: Estudio cualitativo y exploratorio realizado entre mayo y junio de 2018 con madres y cuidadoras de niños nacidos entre 2014 y 2015 de alta de dos unidades neonatales públicas de una capital del Noreste brasileño. Se realizaron 14 entrevistas semiestructuradas y se ha utilizado el análisis de contenido en la modalidad temática. Se ha identificado tres categorías que evidencian los posibles caminos recogidos para el cuidado pasando en su mayoría por los tres sectores: "El sector informal para el punto de inicio del cuidado", "El uso del sector popular para la práctica de cura", "El uso del sector profesional: alternativa para la consulta". Resultados: El sector informal ha sido el más relatado por las cuidadoras. En general, la primera elección era el auto medicación orientada por las generaciones de abuelas. El uso del sector popular ha sido influenciado por el conocimiento previo de las familias y su percepción del proceso salud-enfermedad. La cultura biomédica ha pasado por los tres sectores y ha influenciado para la construcción del itinerario terapéutico. Se ha identificado un vínculo frágil en el sector profesional sobre todo en la atención primaria. Conclusión: Los caminos recogidos por madres y cuidadoras de niños de alta de unidades neonatales señalaron el solapamiento de la medicalización con pérdida de los saberes populares. Acoger y manejar los repertorios sociales y culturales de las familias puede contribuir para reforzar los vínculos terapéuticos con el sector profesional. Hace falta el fortalecimiento de la Atención Primaria de Salud para garantizar la cualificación del cuidado de los niños.

Descriptores: Atención a la Salud; Cuidado del Niño; Medicina Tradicional; Automedicación; Unidades de Cuidado Intensivo Neonatal.

\section{INTRODUÇÃO}

Os progressos científicos em neonatologia possibilitaram avanços tecnológicos que vieram acompanhados de mudanças na assistência e no cuidado ao recém-nascido $(\mathrm{RN})^{(1)}$. A internação neonatal tem contribuído para o aumento da sobrevida, especialmente daqueles que nascem pré-termo e/ou de baixo peso, que apresentam maior risco de mortalidade, infecção, problemas nutricionais e atrasos do desenvolvimento. São problemas complexos e que necessitam, após a alta hospitalar, de acompanhamento compartilhado entre a Atenção Especializada e a Atenção Primária à Saúde (APS). A descontinuidade desse acompanhamento pode levar a maior risco de mortalidade e complicações, inclusive em longo prazo(2,3).

Portanto, ao voltar para o domicílio, essas crianças devem ser cuidadosamente monitoradas, pois podem requerer intervenções planejadas. As famílias, muitas vezes, se deparam com situações não só de medo e insegurança no cuidado do filho, mas também com questões socioculturais voltadas para a dimensão simbólica de sua compreensão sobre saúde. A Política Nacional de Promoção à Saúde, reconhecendo a subjetividade das pessoas e dos coletivos no processo de atenção e cuidado, reforça o conceito ampliado de saúde resultante dos modos de vida, de organização e de produção em determinado contexto histórico, social e cultural, buscando superar a concepção da saúde como ausência de doença, centrada em aspectos biológicos ${ }^{(4)}$. Nessa esfera, evidencia-se a transversalidade da promoção da saúde, que deve ocorrer em todos os cenários da rede de atenção à saúde e sociedade, empregando distintas estratégias de atuação( ${ }^{(4)}$. 
Ao se deslocarem do ambiente de cuidado hospitalar, os usuários se inserem numa complexa rede social, afetiva e simbólica, diante da qual são definidos percursos e caminhos singulares para a continuidade do cuidado no território(5). Influenciam nesse processo: vínculos estabelecidos (ou não) com os profissionais; vínculos familiares e comunitários; conhecimentos, percepções e experiências anteriores; crenças culturais; a rede de relações com o território; o acesso aos serviços de saúde; e aspectos sociais e subjetivos que constituem a contemporaneidade, como cultura digital e medicalização.

O caminho percorrido pelos usuários e suas famílias em busca de tratamento e cura é denominado itinerário terapêutico (IT), que, no cuidado à saúde, é compreendido por três subsistemas inter-relacionados: setor informal, não sistematizado, que abrange os cuidados realizados pela família, comunidade e redes sociais do indivíduo; setor popular, que inclui especialistas da cura ligados a grupos religiosos ou seculares, como benzedeiras, curandeiros, pais de santo, parteiras, entre outros; e setor profissional, que consiste no sistema formal de saúde e compreende as profissões regulamentadas ${ }^{(6)}$.

As mães, na busca de práticas satisfatórias de cuidado, adquirem saberes, experiências e conhecimentos com as pessoas de seu convívio. Destaca-se a transgeracionalidade na transmissão de conhecimentos, em que avós desempenham importante papel(7).

Considerando que a multiplicidade de caminhos e escolhas das famílias influencia diretamente no cuidado a essas crianças ao realizarem seus percursos em busca de atenção e tratamento, buscou-se realizar este estudo. Espera-se, então, contribuir para a promoção da saúde e a ampliação do olhar dos profissionais de saúde às diversidades terapêuticas. Diante disso, este estudo teve a seguinte questão norteadora: Quais são os caminhos percorridos pelas famílias após a alta na busca por cuidados com a saúde de crianças egressas de unidades neonatais?

O objetivo deste estudo foi compreender os caminhos percorridos por mães e cuidadoras na busca pelo cuidado de crianças egressas de unidades neonatais.

\section{MÉTODOS}

Estudo qualitativo(8) e de caráter exploratório, realizado no período de maio a junho de 2018 , com mães e cuidadoras de crianças egressas de duas unidades neonatais (UN) públicas de uma capital do Nordeste brasileiro.

Foram identificadas 165 crianças a partir da análise dos prontuários, na qual a escolha dos participantes buscou privilegiar os diferentes atributos significativos para o objeto de estudo( ${ }^{(8)}$. Os critérios de inclusão foram: ser mãe e/ou cuidador de crianças nascidas entre 2014 e 2015, egressas de internação em UN e residentes no município de realização da pesquisa, sendo o ponto de partida para sua identificação os prontuários das crianças. Os critérios para exclusão foram crianças nascidas fora do período mencionado nos critérios de inclusão. Assim, foram previamente selecionadas 34 crianças residentes nos diferentes distritos sanitários e iniciadas as entrevistas com as mães até atingir o critério de saturação, momento do trabalho de campo no qual os dados obtidos são suficientes para a compreensão, pelo pesquisador, da lógica interna do grupo pesquisado. Dessa forma, o fechamento amostral ocorreu com 14 entrevistas.

O primeiro contato com as mães e cuidadoras ocorreu por telefone. Nesta ocasião era realizada a apresentação da pesquisadora e dos objetivos da pesquisa e realizado o convite para participar. Não houve nenhuma recusa entre as mães contatadas. Após o aceite, era agendada a entrevista em horário e local convenientes para as entrevistadas. O local preferencial para realização das entrevistas foi o domicílio. Apenas uma optou pelo ambulatório de seguimento.

As técnicas utilizadas para coleta de dados foram: questionário estruturado, preenchido com dados extraídos do prontuário, para identificação dos dados do nascimento e condições clínicas das crianças, e entrevista semiestruturada realizada com as mães e cuidadoras. Para as entrevistas foi elaborado um roteiro contendo perguntas fechadas acerca dos dados sociodemográficos das mães e cuidadoras (idade, escolaridade, situação conjugal, renda, número de filhos e religião). Já com relação às crianças foram selecionados os seguintes dados: idade, sexo, tempo de internação e diagnóstico, e a questão norteadora: Quais são os caminhos percorridos pelas famílias após a alta na busca por cuidados com a saúde de crianças egressas de unidades neonatais?

As entrevistas foram gravadas e, posteriormente, transcritas. As entrevistadas demonstraram disponibilidade e interesse em falar sobre suas práticas, deixando evidente a importância de serem escutadas. As entrevistas ocorreram em local reservado, em um clima de cordialidade entre entrevistadora e entrevistada, e tiveram a duração aproximada de 30 minutos.

Para a análise e interpretação de dados utilizou-se a análise de conteúdo na modalidade temática( ${ }^{(9)}$, que se entende como um conjunto de técnicas de análise das comunicações visando obter, por meio de procedimentos sistemáticos e objetivos de descrição do conteúdo das mensagens, indicadores (quantitativos ou não) que permitam a inferência de conhecimentos relativos às condições de produção/recepção dessas mensagens. 
A primeira fase se caracteriza como pré-análise, momento em que ocorrem a leitura flutuante e exaustiva das falas. A segunda fase é de exploração do material, buscando, a partir das categorias analíticas, os núcleos temáticos, que são expressões ou palavras significativas em função das quais o conteúdo de uma fala foi organizado. Na fase final foram realizadas inferências e interpretações, articuladas com o quadro teórico desenhado inicialmente e em torno de novas dimensões teóricas e interpretativas ${ }^{(9)}$, permitindo o reconhecimento de três núcleos temáticos: "O setor informal como ponto de partida para o cuidado"; "O uso do setor popular como prática de cura"; "O uso do setor profissional: alternativa para consulta".

Este estudo faz parte de uma pesquisa maior intitulada "Setores de cuidado de saúde utilizados por crianças egressas de unidades neonatais", aprovada pelo Comitê de Ética em Pesquisa do Hospital Universitário da Universidade Federal do Maranhão (HUUFMA), Parecer $n .^{\circ}$ 2.626.632. Os nomes das participantes foram substituídos por nomes fictícios, garantindo o anonimato e a confidencialidade das informações.

\section{RESULTADOS E DISCUSSÃO}

\section{Dados sociodemográficos das entrevistadas e de identificação das crianças}

Das 14 entrevistas, 13 foram realizadas com as mães e uma com a avó materna, que era a cuidadora principal da criança. A idade variou entre 16 e 64 anos, a maioria de religião católica, com ensino fundamental incompleto. Seis viviam em união consensual, cinco sem companheiros e as demais casadas, viúvas ou divorciadas. O número de filhos variou, majoritariamente, entre um e quatro. A renda familiar variou de menos de um a quatro salários mínimos. Oito afirmaram receber o benefício bolsa família.

Com relação às crianças, no momento da entrevista, as crianças possuíam entre 34 e 47 meses de vida e oito eram primogênitos, com predomínio do sexo masculino. O tempo de internação na UN variou de 2 a 110 dias, sendo o principal diagnóstico a prematuridade. Outros diagnósticos foram: síndrome da aspiração meconial, desconforto respiratório, doença hemorrágica, policitemia, taquipneia transitória do $\mathrm{RN}$, anóxia, fenda palatina e lábio leporino. Duas crianças tinham diagnóstico de paralisia cerebral, e outra saiu do hospital traqueostomizada.

Considerando-se que as crianças foram identificadas no setor profissional e que passaram por internação neonatal em serviços de alta complexidade, esperava-se que utilizassem regularmente a Atenção Especializada e a APS, no entanto apenas três crianças estavam em acompanhamento no ambulatório especializado e duas referiram vinculação com a APS.

Pelas entrevistas, apurou-se que, no momento da alta, após a internação neonatal, todas foram encaminhadas para a unidade básica de referência ou seguimento em ambulatório especializado. A partir dos IT construídos nas entrevistas, verificou-se sobreposição do uso dos setores de atenção à saúde (profissional, popular e informal), expressa de várias formas e atravessada por uma lógica cultural que evidenciou os possíveis caminhos percorridos por mães e cuidadoras para o cuidado das crianças. A análise dos IT não seguiu modelos e padrões fixos, que deixariam de lado a dinamicidade dos processos. As concepções, escolhas e estratégias de enfrentamento das situações de adoecimento são processos construídos pelos sujeitos e por suas redes relacionais, que vão desde família e amigos até os serviços de saúde, na cultura em que estão inseridos ${ }^{(10)}$.

A seguir, esses caminhos serão apresentados a partir dos núcleos temáticos que emergiram do estudo: "O setor informal como ponto de partida para o cuidado"; "O uso do setor popular como prática de cura"; "O uso do setor profissional: alternativa para consulta".

\section{O setor informal como ponto de partida para o cuidado}

Esta categoria evidencia que as primeiras escolhas, no momento inicial de identificação da doença, foram práticas do setor informal. Entre essas práticas, foram citadas: automedicação, remédios caseiros e aconselhamento com pessoas que possuem experiência parecida, sendo a automedicação mais frequente:

"Mas sempre tem guardado! Que mamãe sempre fala para "mim" ter os remédios guardados. Minha mãe sempre pede para "mim" guardar. Caso ele tenha febre, para "mim" dar um remédio para ele." (mãe de Lucas)

"Remédio para febre... eu dou remédio para tosse também. Normalmente, eu dou por conta própria. Aí, se eu vejo que não deu resultado, aí eu levo ele ao médico." (mãe de Davi)

Para algumas cuidadoras, a automedicação era decorrente da orientação recebida por parentes, em especial pelas avós, que participavam diretamente do cuidado, mas também foi evidenciada a utilização de antigas prescrições, como observado nas falas abaixo: 
"Mas se for um problema que eu já sei o que é e, se for levar no hospital, vai ser a mesma conduta, eu não levo. Porque eu já tenho todas as receitas, eu vou lá na farmácia." (mãe de Manoel)

"Porque o médico passou, eu fui e comprei dois vidros, guardo um em casa. Quando eu vejo que ele deve estar com a garganta inflamada, eu vou de acordo com o medicamento. E paracetamol sempre tenho em casa... dipirona, que eu sei que ele pode tomar." (mãe de Paulo)

Neste estudo, o setor informal foi relatado por mães que possuíam maior ligação com o setor profissional. Para elas, o reaparecimento de sinais e sintomas anteriormente diagnosticados e tratados justificavam o uso de antigas prescrições. Essa prática, utilizada por cuidadores de crianças que fazem acompanhamento médico mais frequente, tem sido descrita na literatura, a exemplo de estudo que abordou uso de automedicação em menores de 12 anos, que evidenciou maior uso no Norte e Nordeste ${ }^{(11)}$.

Outra prática encontrada foi a busca de orientação para aquisição de medicamentos na farmácia do bairro, como observado a seguir:

"A minha sogra manda comprar remédio, eu dou para ela. Ela foi lá na farmácia, aí eles passaram." (mãe de Ana)

"Vou à farmácia, explico... aí a moça passa um remedinho que é bom para isso... para diarreia, né? Aí eu dei e foi melhorando... aí eu dava também água de coco... ai melhorou." (mãe de Pedro)

No Brasil, é comum que balconistas de drogarias desempenhem papel de prescritores ${ }^{(12)}$, não ficando claro nas entrevistas se a orientação foi dada por balconista ou farmacêutico.

Estudo realizado em estabelecimento comercial farmacêutico no Ceará demonstrou que balconistas de farmácia exerceram forte influência sobre a automedicação e que familiares e amigos foram os mais influenciadores dessa prática. A praticidade foi descrita como motivação, já que é mais fácil adquirir o medicamento na farmácia do que marcar uma consulta médica(12).

As famílias são muito importantes no processo do cuidar, portanto, tornase relevante avaliar o contexto em que estão inseridas, a fim de sejam verificadas as formas de tratamento e promovidas a busca do cuidar por elas ${ }^{(13)}$.

Em um estudo, verificou-se nas falas que o sistema informal é buscado no cotidiano das famílias dessas crianças, apontando que a cultura impacta na resolução do processo de adoecimento, isto é, como cada família organiza seus costumes e promove os cuidados para reestabelecimento da saúde ${ }^{(13)}$.

Assim, foram mencionadas práticas utilizadas, como chás e remédios caseiros, especialmente influenciadas, de forma transgeracional, pelas avós maternas, que participavam diretamente do cuidado com a criança:

"É porque... a minha mãe é do interior, então sempre usava... plantas medicinais, remédios naturais... para curar enfermidades, doenças do tipo... gripe. É muito comum! Eles usam muito lambedor... e, hoje em dia, eu passei isso para meu filho, entendeu? E eu vejo resultado, não é?" (mãe de Yago)

"Porque mamãe disse que antigamente não tinha farmácia, era os remédios caseiros, não é? Os mais velhos davam para gente. Aí, com isso, ela manda eu fazer: 'olha minha filha, faz assim."' (mãe de Saulo)

Na literatura, a utilização de medidas caseiras por cuidadores, especialmente o uso de chás, também é comumente citada $^{(14,15)}$. Em algumas situações, ao perceber a doença, o uso de chás, banhos de ervas e xaropes são considerados a primeira escolha ${ }^{(6)}$, sendo com frequência administrados concomitantemente a outros medicamentos ${ }^{(16)}$. No geral, esse aprendizado foi adquirido através da observação e pela troca de informações entre familiares, especialmente mães e sogras ${ }^{(17)}$, seguidas de avós e tias, o que corrobora os dados encontrados.

Práticas ligadas à religião, como oração e uso de óleo ungido, também aparecem como recursos utilizados pelas cuidadoras para obtenção de cura nos momentos de aflição:

"Mas eu oro demais quando eles estão doentes. Às vezes, eu faço campanha de oração quando vejo que eles tão muito doentes. Eu vou lá nas irmãs e digo: 'irmãs, quero campanha de oração, os meninos tão doentes demais." (mãe de Saulo)

"Um dia ele estava assim, com febre, não estava dormindo direito... aí eu usei o óleo ungido nele. Eu senti certa melhora, não é?! Ele melhorou, graças a Deus! Dormiu bem. Então, nessas horas assim que eu costumo usar a fé em Deus, não é?!" (mãe de Yago)

As religiões modificam a maneira pela qual os indivíduos se posicionam frente à doença e seu tratamento(18), assumindo grande relevância, especialmente, para populações de baixa renda ${ }^{(5)}$. 
Ainda relacionado ao setor informal, duas mães relataram o compartilhamento de informações e orientação com outras que tiveram experiências semelhantes:

"A menina bem aqui em frente. Ela tem um neném especial também. Ele já tinha usado sonda muito tempo, e ela sempre me dava dica assim... alguma coisa que eu não sabia, ela me dizia." (mãe de Elis)

Percebe-se que a forma de enfrentar a doença e de minimizar os impactos de eventos imprevistos sobre a saúde dos indivíduos está relacionada também à capacidade individual de tomar decisões, mesmo havendo influência das concepções de saúde, da doença e do corpo, e também dos recursos de saúde disponíveis e da dificuldade de acesso aos serviços de saúde ${ }^{(10)}$. Além disso, é possível que o não reconhecimento do uso dos outros setores pelos profissionais de saúde também possa influenciar na escolha inicial pelo setor informal(14).

Estudo sobre IT de menores de cinco anos, em resposta aos agravos à saúde, encontrou que $74,58 \%$ dos episódios referidos como doenças foram tratados, inicialmente, em casa ${ }^{(16)}$. Mesmo quando se trata da criança que nasceu prematura, cujas mães procuram assistência em diversos setores, o setor informal ainda costuma ser o primeiro buscado e, em geral, direciona o IT a ser percorrido(13).

Um dos desdobramentos da biomedicina é a medicamentalização (jargão criado para se referir ao controle médico da mente). A racionalidade biomédica atrelada à lógica concorrencial e de alta performance criou condições para a cultura da automedicação, que põe em cena não só o saber médico em si, mas a poderosa indústria farmacológica. A dificuldade de acesso a profissionais de saúde e a desqualificação dos saberes tradicionais criam uma espécie de pressão sobre o setor informal, que encontra como principal recurso cotidiano a automedicação(19).

\section{O uso do setor popular como prática de cura}

Esta categoria evidencia que, mesmo se tratando de crianças egressas de UN, algumas com comorbidades, as práticas do setor popular são referidas neste estudo, ainda que não predominantes.

As mães citaram a utilização de práticas populares para o tratamento de problemas associados a questões culturais, a exemplo de "mau olhado", "quebrante" e "vento virado":

"A gente estava suspeitando de mau olhado, não é?! Levei ela lá na moça para benzer... (mãe de Mel)

"Ela estava com dois meses, eu acho, aí a gente saiu. Aí, quando a gente voltou, ela começou a ficar doente... do nada. Ela estava vomitando, molinha, não estava mamando direito... aí a gente começou: 'botaram quebrante' e não era. Era vento virado." (mãe de Ana)

O benzimento foi, e ainda é, uma prática de cura bastante difundida e reconhecida socialmente, especialmente para o cuidado de crianças. Envolve saberes populares que são transmitidos de geração a geração( ${ }^{(7,20)}$. No entanto a medicina popular tem sido buscada como alternativa ou como forma de complementar o tratamento da medicina tradicional, mesmo por pessoas com acesso à educação formal e ao saber médico ${ }^{(20)}$.

Para uma das cuidadoras, o "quebrante" foi colocado pelos vizinhos e reconhecido por familiares, que indicaram a benzedura como tratamento:

"Ela já pegou quebrante, essas coisas assim. Logo quando ela chegou, que ela era gordona mesmo! Aí os curiosos aqui da rua, todo mundo queria ver como ela era. Aí vieram aqui e botaram quebrante nela." (mãe de Elis)

Para algumas mães, essas doenças não são tratadas no setor profissional. São doenças que o médico não conhece e que os serviços de saúde não têm competência para tratar ${ }^{(16)}$. No entanto isso não foi consenso. $A$ utilização do setor profissional foi citada, em algumas situações, quando as práticas do setor popular não produziam o resultado esperado:

"Aí mamãe disse: 'se ela não melhorar daqui para mais tarde, tu levas ela no hospital'." (mãe de Mel)

É importante destacar a pluralidade do uso de setores. Mesmo benzedeiras, cujo objetivo é ajudar a todos que as procuram, curando doenças do corpo e da alma, algumas vezes, recomendam a busca por tratamento médico especializado ${ }^{(20)}$.

Para além dos setores buscados, talvez o mais importante seja perguntar sobre que racionalidade ou lógica de gestão da vida tais setores estão constituídos. Os sistemas de significações e sentidos da doença acabam se restringindo ao campo da intervenção médica, que fagocita os demais campos de significação e sentidos. Constrói-se 
a verdade científica e a autoridade do saber médico, que avalia negativamente qualquer concepção da doença que não esteja de acordo com as evidências das ciências biológicas contemporâneas ${ }^{(10)}$.

É comum o saber médico apresentar reservas quanto a essas práticas, dificultando uma aproximação entre os saberes ${ }^{(7,13,21)}$. Como qualquer prática voltada à saúde, algumas podem não ser benéficas ${ }^{(15)}$. Assim, é importante que profissionais de saúde abordem essa temática de modo transparente e aberto, reconhecendo que as dimensões do cuidado vão além do saber científico ${ }^{(13,15)}$.

A perspectiva da promoção à saúde possibilitaria a inserção de práticas e saberes populares nos territórios, que poderiam ser mediadas pelo setor profissional por meio de práticas integrativas e complementares (PIC), por exemplo. Em estudo com crianças em tratamento oncológico, a busca pelas PIC foi uma alternativa terapêutica motivada pela procura de outras formas de cuidado, prevenção e melhor qualidade de vida, com caráter complementar ao tratamento convencional(21).

Dar visibilidade a outras práticas, não hegemônicas, de cuidado não significa excluir a prática biomédica, mas ir além dessa "cultura do cuidado" para se abrir ao "cuidado na cultura", respeitando as diversidades e o pluralismo terapêutico, valorizando a totalidade de sentidos e se abrindo para o encontro, para o cuidado da cultura(10).

\section{O uso do setor profissional: alternativa para consulta}

Esta categoria evidencia a fragilidade do vínculo das mães e cuidadoras de crianças egressas de internação em unidades neonatais com o setor profissional, especialmente com a APS.

As entrevistadas pouco reconheceram o setor profissional como principal local de cuidado da saúde dos filhos. Apenas uma mãe e uma avó afirmaram não utilizar remédios caseiros nem medicamentos sem conhecimento do médico pelo medo da criança passar mal ou agravar o quadro clínico. Das que afirmaram utilizar os serviços de atenção primária em algum momento, os motivos mais citados foram: consultas motivadas por um problema específico e vacinação. A frequência de agendamento das consultas não atendia à regularidade recomendada para cada criança. Era determinada pela cuidadora, de acordo com sua avaliação de necessidade de atendimento:

"Às vezes, eu levo ele no posto para consultar, mas é só às vezes. Quando a agente de saúde passa, aí marca, então eu levo ele." (mãe de Lucas)

"Depende, se eu achar que ele já está com... uma vermezinha... levo ele no posto para fazer um exame. Mas normalmente não faz lá. Eu faço particular e levo para o médico do posto." (mãe de Davi)

"Quando a gente marca a consulta dela é no posto mesmo. Eu levo assim, mês em mês, de dois em dois meses..." (avó de Rebeca)

É necessário destacar que essas crianças, no momento da alta, receberam orientações para a realização de consultas regulares na APS, e também aquelas com indicação para acompanhamento em ambulatório especializado. Considerando a importância do seguimento das crianças nos primeiros 1.000 dias (período que vai da concepção até 2 anos) para a promoção de sua saúde e qualidade de vida, o não comparecimento regular precisa ser compreendido e pode ter, em sua gênese, questões relacionadas à cobertura da Estratégia Saúde da Família (ESF), que, no local do estudo, é de aproximadamente de $43 \%{ }^{(22)}$, assim como questões relacionadas ao processo de trabalho e à própria percepção das equipes da ESF sobre sua capacidade de atuação no cuidado dessas crianças que nasceram em situação de risco ${ }^{(3)}$.

Das crianças vinculadas ao ambulatório de seguimento especializado, nenhuma cuidadora referiu utilizar os serviços da APS e apenas duas entrevistadas afirmaram receber visita de agente comunitário de saúde. Estudos realizados com profissionais de saúde da APS apontaram que, no atendimento da criança egressa de unidade neonatal, faz-se importante a realização de trabalho articulado em rede, preconizando a comunicação antecipada entre maternidade e APS ${ }^{(3,23)}$.

O setor profissional foi utilizado, principalmente, em situações de intercorrência ou urgência, associadas com a avaliação de gravidade realizada pelas próprias cuidadoras:

"Quando eu vejo, assim, que é um caso muito grave, como tipo... uma pancada, um ferimento, ou vejo que ele tá muito cansado, aí eu já levo ele no hospital. Ou quando vejo que a corzinha do xixi dele está diferente, ou está com alguma dor, aí eu já levo no médico para saber o que é, se é uma infecção. Nesse caso, eu procuro profissionais." (mãe de Yago)

"Oh! Eu conheço ele! Só levo mesmo assim... quando ele não está bem mesmo, quando está dando febre com três dias, aí eu já procuro levar para o médico." (mãe de Davi)

"Quando ela está vomitando, quando está tendo febre... aí é que eu levo [no hospital]." (mãe de Ana) 
O entendimento de gravidade é subjetivo e sua diferenciação é baseada na experiência acumulada pela própria vivência, por hábitos culturais, pelo conhecimento incorporado no contato com profissionais da saúde, pela convivência e intercâmbio de conhecimentos e experiências com conhecidos ${ }^{(16)}$.

A porta de entrada mais utilizada no setor profissional foram os serviços de urgência e emergência. A principal motivação para essa escolha foi a facilidade de acesso, resolutividade e experiências prévias, ainda que, muitas vezes, fossem casos possíveis de resolução na APS:

"Eu gosto mesmo de levar é na UPA, que eu acho o atendimento lá melhor. [...] Levo só mesmo quando ele tá doente, porque, quando eu vou lá, eu peço pro médico logo fazer exame nele pra ver como ele está." (mãe de Tiago)

"Vovó prefere mais é médico, ela quer que leve logo é no médico. Ela: 'Ah, vamos na UPA, leva logo na UPA." (mãe de Pedro)

A percepção singularizada da doença e o medo da piora aliados à certeza de atendimento resolutivo são fatores decisivos para a procura pelos serviços de urgência e emergência(23). O usuário busca o serviço para solução de necessidades que, naquele momento, trazem angústia e desconforto, ainda que não sejam causas urgentes, principalmente se tratando de menores de 5 anos $^{(24)}$.

A interpretação do que é relevante, do que causa ou evita um problema e do tipo de ação necessária é, para os profissionais de saúde, determinada pelos conhecimentos biomédicos. Porém, para os indivíduos, é determinada pelas redes de símbolos que articulam conceitos biomédicos e culturais, que determinam formas características de pensar e agir frente a um problema de saúde específico(6).

A diminuição da autonomia e da capacidade de autocuidado se dão pela medicalização da vida como processo que produz, a partir do saber médico, um aumento da dependência individual e coletiva relacionada ao processo saúde-doença(25).

É fundamental valorizar o saber familiar e o contexto cultural das famílias para garantir orientações e acompanhamento adequados ${ }^{(15,26)}$. O diálogo entre os diferentes setores de atenção à saúde fortalece o vínculo entre profissionais e usuários e possibilita ações voltadas para a promoção da saúde, que devem criar espaços de discussão e possibilitar que as mães e cuidadores falem de seus saberes e modos de cuidar. A adesão e motivação para mudança de hábitos, comportamentos e práticas culturais não são modeladas passivamente. Para que isto ocorra, é importante que a promoção da saúde seja fundamentada em trocas que integrem o saber científico com os saberes populares de saúde ${ }^{(27)}$.

Considerando que um dos objetivos da Política Nacional de Promoção da Saúde é valorizar os saberes populares e tradicionais, espera-se que os resultados desta pesquisa possibilitem a reflexão dos profissionais da atenção hospitalar e da APS, contribuindo para o seu fortalecimento e impactando na qualidade da assistência(4).

Esta pesquisa teve como principal limitação a escolha, pelas entrevistadas, do domicílio como local escolhido para realização das entrevistas. A presença de outras pessoas, em especial avós e tias, pode ter influenciado suas respostas. Outra potencial limitação, superada com o estabelecimento de relação de confiança durante as entrevistas, foi a dificuldade inicial demonstrada pelas entrevistadas de falarem das práticas ligadas aos setores informal e popular por medo de julgamento.

\section{CONSIDERAÇÕES FINAIS}

Conhecer o itinerário terapêutico de crianças egressas de UN permitiu compreender os caminhos percorridos por mães e cuidadoras na busca pelo cuidado. As famílias entrevistadas utilizaram todos os setores de atenção à saúde, mas o setor informal foi o mais utilizado e, em geral, direcionou o IT, motivado pelo conhecimento prévio das famílias e por sua percepção do processo saúde-doença, que influenciaram seu modo de agir.

Foram identificados vínculos frágeis com o setor profissional, principalmente com a APS, evidenciando obstáculos organizacionais e dificuldades de acesso, que influenciaram nesse processo. O vínculo com os profissionais que acompanham as crianças na atenção hospitalar pareceu mais estabelecido.

A interferência da cultura biomédica perpassou os três setores e também influenciou o IT. Acolher e manejar os repertórios sociais e culturais das famílias em projetos terapêuticos singulares parece ser uma estratégia clínica fundamental para que os acúmulos do setor profissional sejam bem utilizados e não se transformem em barreira à autonomia dos usuários. 


\section{CONFLITOS DE INTERESSE}

Os autores declaram não haver conflitos de interesses.

\section{AGRADECIMENTOS}

Os autores agradecem à Fundação de Amparo à Pesquisa e ao Desenvolvimento Científico e Tecnológico do Maranhão (FAPEMA) pelo financiamento, ao Conselho Nacional de Desenvolvimento Científico e Tecnológico (CNPq) pelas bolsas de iniciação científica e à Coordenação de Aperfeiçoamento de Pessoal de Nível Superior (CAPES).

\section{FINANCIAMENTO}

Fundação de Amparo à Pesquisa e ao Desenvolvimento Científico e Tecnológico do Maranhão (FAPEMA); Conselho Nacional de Desenvolvimento Científico e Tecnológico (CNPq); Coordenação de Aperfeiçoamento de Pessoal de Nível Superior (CAPES) - Finance Code 001.

Artigo baseado na dissertação de mestrado intitulada "Setores de cuidado à saúde: vivências de famílias egressas de Unidade Neonatal da Universidade Federal do Maranhão”. 2019. 73 páginas.

\section{CONTRIBUIÇÕES}

Hortênsia Coutinho da Rocha, Zeni Carvalho Lamy, Lia Cardoso de Aguiar e Fernando Lamy-Filho contribuíram com a elaboração e delineamento do estudo; a aquisição, análise e interpretação dos dados; e a redação e/ou revisão do manuscrito. Joama Gusmão Pereira Moreira, Marina Uchoa Lopes Pereira, Yanca Lacerda Albuquerque e Tadeu de Paula Souza contribuíram com a aquisição, análise e interpretação dos dados; e a redação e/ou revisão do manuscrito.

\section{REFERENNCIAS}

1. Sousa DS, Sousa AS Júnior, Santos ADR, Melo EV, Lima SO, Almeida-Santos MA, et al. Morbidade em recém-nascidos prematuros de extremo baixo peso em unidade de terapia intensiva neonatal. Rev Bras Saúde Matern Infant [Internet]. 2017 [acesso em 2020 Out 03];17(1):139-47. Disponível em: https://www. scielo.br/scielo.php?pid=S1519-38292017000100139\&script=sci_arttext\&tlng=pt

2. Barkemeyer BM. Discharge planning. Pediatr Clin [Internet]. 2015 [acesso em 2020 Out 03];62(2):545-56. Disponível em: https://www.pediatric.theclinics.com/article/S0031-3955(14)00258-2/abstract

3. Silva MS, Lamy ZC, Simões VMF, Pereira MUL, Campelo CMC, Gonçalves LLM. Acompanhamento na terceira etapa do Método Canguru: desafios na articulação de dois níveis da atenção. Rev Baiana Saúde Pública [Internet] 2018 [acesso em 2020 Nov 19];42(4):671-85. Disponível em: http://www.rbsp.sesab.ba.gov. br/index.php/rbsp/article/view/3033

4. Ministério da Saúde (BR). Política Nacional de Promoção da Saúde: PNPS: Anexo I da Portaria de Consolidação no 2, de 28 de setembro de 2017, que consolida as normas sobre as políticas nacionais de saúde do SUS [Internet]. Brasília: Ministério da Saúde; 2018 [acesso em 2020 Nov 19]. Disponível em: http:// bvsms.saude.gov.br/bvs/publicacoes/politica_nacional_promocao_saude.pdf

5. Ferreira J, Espírito Santo W. Os percursos da cura: abordagem antropológica sobre os itinerários terapêuticos dos moradores do complexo de favelas de Manguinhos, Rio de Janeiro. Physis (Rio J) [Internet]. 2012 [acesso em 2020 Out 03];22(1):179-98. Disponível em: https://www.scielo.br/scielo.php?pid=S0103$73312012000100010 \&$ script $=$ sci_arttext\&tlng=pt

6. Alves PC. Itinerário terapêutico e os nexus de significados da doença. Rev Ciênc Soc [Internet]. 2015 [acesso em 2020 Out 03];(42):29-43. Disponível em: https://www.siga.fiocruz.br/arquivos/ss/documentos/editais/4_ artigo2 alves paulo cesar.pdf

7. Takemoto AY, Zarpelon NF, Rossetto EG. Popular practices in child care: mothers' perceptions. Rev RENE [Internet]. 2019 [acesso em 2020 Out 03];20:e40075. Disponível em: http://periodicos.ufc.br/rene/article/ view/40075 
8. Minayo MCS. O desafio do conhecimento: pesquisa qualitativa em saúde. São Paulo: Hucitec-Abrasco; 2014.

9. Bardin L. Análise de Conteúdo. Lisboa: Edições 70; 2016.

10. Gerhardt TE, Ruiz ENF. Itinerários terapêuticos: dispositivo revelador da cultura do cuidado e do cuidado na e da cultura. In: Pinheiro R, Gerhardt TE, Silva Junior AG, Di Leo PF, Ponce M, Venturiello MP. Cultura do Cuidado e o Cuidado na cultura: dilemas, desafios e avanços para efetivação da integralidade em saúde no MERCOSUL. Rio de Janeiro: UERJ; 2014. p. 255-70.

11. Pizzol T da SD, Tavares NUL, Bertoldi AD, Farias MR, Arrais PSD, Ramos LR, et al. Uso de medicamentos e outros produtos com finalidade terapêutica entre crianças no Brasil. Rev Saúde Pública [Internet]. 2016 [acesso em 2020 Out 03];50:12s. Disponível em: https://www.scielosp.org/article/rsp/2016.v50suppl2/12s/pt/

12. Duarte D'A, Malta A Júnior. Perfil da automedicação em uma farmácia de dispensação em Barbalha-CE. Rev e-Ciência [Internet]. 2016 [acesso em 2020 Out 03];3(2):66-73. Disponível em: http://www.revistafjn.com.br/ revista/index.php/eciencia/article/view/65

13. Morais AC, Silva ACOC, Almeida CR, Lima KDF. Itinerário terapêutico de mães de crianças egressas do Método Canguru. Ciênc Cuid Saúde [Internet]. 2017 [acesso em 2020 Out 03];16(2):e35994. Disponível em: http://periodicos.uem.br/ojs/index.php/CiencCuidSaude/article/view/35994

14. Freire CJ, Barbosa LRS, Costa JG, Santos RGA, Santos AF. Fitoterapia em pediatria: a produção de saberes e práticas na Atenção Básica. Rev Bras Enferm [Internet]. 2018 [acesso em 2020 Out 03];71(Suppl:637-45. Disponível em: https://www.scielo.br/scielo.php?pid=S0034-71672018000700637\&script=sci_arttext\&tlng=pt

15. Brondani KJM, Ferrari RAP, Cardelli AAM, Tacla MTGM, Dalmas JC, Fançoso FG. Práticas maternas e uso de terapias alternativas no cuidado da criança. Cogitare Enferm [Internet]. 2018 [acesso em 2020 Out 03];23(4):e54090. Disponível em: https://revistas.ufpr.br/cogitare/article/view/54090

16. Leite SN, Vasconcellos MP. Medicamentos e outros recursos utilizados no enfrentamento das doenças infantis no cotidiano familiar: estudo qualitativo. Acta Farm Bonaer [Internet]. 2009 [acesso em 2020 Out 03];28(6):835-42. Disponível em: http://www.latamjpharm.org/trabajos/28/6/LAJOP_28_6_1_5_GP431AB041. pdf

17. Lima R, Turrini R, Silva LR, Melo L, Augusto SI. Popular healing practices and medical plants use for riparian mothers in early childhood care. Rev Pesqui (Univ Fed Estado Rio J) [Internet]. 2017 [acesso em 2020 Out 03];9(4):1154-63. Disponível em: http://www.seer.unirio.br/index.php/cuidadofundamental/article/view/5982

18. Abu-Raiya H, Pargament KI. Religious coping among diverse religions: Commonalities and divergences. Psycholog Relig Spiritual [Internet]. 2015 [acesso em 2020 Out 03];7(1):24-33. Disponível em: https://psycnet. apa.org/journals/rel/7/1/24/

19. Silva LM, Canavêz F. O Estudo da Medicalização da Vida e suas Implicações para a Clínica Contemporânea. Rev Subj [Internet]. 2018 [acesso em 2020 Out 03];17(3):117-29. Disponível em: https://periodicos.unifor.br/ rmes/article/view/5813

20. Hoffmann-Horochovski MT. Benzeduras, garrafadas e costuras: considerações sobre a prática da benzeção. Guaju [Internet]. 2015 [acesso em 2020 Out 03];1(2):110-26. Disponível em: https://revistas.ufpr.br/guaju/ article/view/45038

21. Costa ARFC, Rocha RS, Feitosa RMM, Oliveira KKD, Coelho WAC. Práticas integrativas e complementares em saúde no cotidiano de crianças com câncer. Rev Enferm Atual In Derme [Internet] 2020 [acesso em 2020 Nov 19];92(30):52-62. Disponível em: http://revistaenfermagematual.com/index.php/revista/article/view/602

22. Ministério da saúde (BR). e-Gestor Atenção Básica: relatório de Cobertura na Atenção Básica [Internet]. Brasília: Ministério da saúde; 2017 [acesso em 2020 Out 2]. Disponível em: https://egestorab.saude.gov.br/ paginas/acessoPublico/relatorios/relHistoricoCoberturaAB.xhtml

23. Aires LCP, Santos EKA, Bruggemann OM, Backes MTS, Costa R. Reference and counter-reference health care system of infant discharged from neonatal unit: perceptions of primary care health professionals. Esc Anna Nery Rev Enferm [Internet]. 2017 [acesso em 2020 Out 03];21(2):e20170028. Disponível em: http:// eean.edu.br/2017/detalhe_artigo.asp?id=1499 
24. Rizzieri TL. Emergências Pediátricas: revisão Integrativa da Literatura. Rev Saúde Foco [Internet]. 2017 [acesso em 2020 Out 03];9:527-32. Disponível em: http://portal.unisepe.com.br/unifia/wp-content/uploads/ sites/10001/2018/06/060_emergencias_pediatricas.pdf

25. Tesser CD, Poli P Neto, Campos GWS. Acolhimento e (des) medicalização social: um desafio para as equipes de saúde da família. Ciênc Saude Colet [Internet]. 2010 [acesso em 2020 Out 03];15:3615-24. Disponível em: https://www.scielosp.org/article/csc/2010.v15suppl3/3615-3624/pt/

26. Góes FGB, Silva MA, Santos AST, Pontes BF, Lucchese I, Silva MT. Cuidado pós-natal de recém-nascidos no contexto da família: revisão integrativa. Rev Bras Enferm [Internet]. 2020 [acesso em 2020 Nov 19];73(Supp. 4):e20190454. Disponivel em: https://www.scielo.br/scielo.php?pid=S0034-71672020001600304\&script=sci_ arttext\&tlng=pt

27. Jesus ACP, Bandeira LPL, Araújo MFM, Amaral Gubert F, Vieira NFC, Rebouças CBA. Popular knowledge in care of the newborn with focus on health promotion. Rev Pesqui (Univ Fed Estado Rio J) [Internet]. 2013 [acesso em 2020 Nov 19];5(2):3626-35. Disponível em: http://www.seer.unirio.br/index.php/ cuidadofundamental/article/view/2271/0

\section{Endereço do primeiro autor:}

Hortênsia Coutinho da Rocha

Universidade Federal do Maranhão - Departamento de Saúde Pública

Rua Barão de Itapari, 155

Bairro: Centro

CEP: 65020-070 - São Luís - MA - Brasil

E-mail: hortensiacr@gmail.com

\section{Endereço para correspondência:}

Marina Uchoa Lopes Pereira

Universidade Federal do Maranhão - Departamento de Saúde Pública

Rua Barão de Itapari, 155

Bairro: Centro

CEP: 65020-070 - São Luís - MA - Brasil

E-mail: ulpmarina@gmail.com

Como citar: Rocha HC, Lamy ZC, Aguiar LC, Moreira JGP, Pereira MUL, Albuquerque YL, et al. Busca por cuidados de saúde: itinerário terapêutico de crianças egressas de unidades neonatais. Rev Bras Promoç Saúde. 2021;34:11708. 